University of Montana

ScholarWorks at University of Montana

$5-1-2000$

\title{
Outcrossing Rate and Inbreeding Depression in the Perennial Yellow Bush Lupine, Lupinus arboreus (Fabaceae)
}

\author{
Pamela Kittelson \\ Gustavus Adolphus College \\ John L. Maron \\ University of Montana - Missoula, john.maron@mso.umt.edu
}

Follow this and additional works at: https://scholarworks.umt.edu/biosci_pubs

Part of the Biology Commons

Let us know how access to this document benefits you.

\author{
Recommended Citation \\ Kittelson, Pamela and Maron, John L., "Outcrossing Rate and Inbreeding Depression in the Perennial \\ Yellow Bush Lupine, Lupinus arboreus (Fabaceae)" (2000). Biological Sciences Faculty Publications. 343. \\ https://scholarworks.umt.edu/biosci_pubs/343
}

This Article is brought to you for free and open access by the Biological Sciences at ScholarWorks at University of Montana. It has been accepted for inclusion in Biological Sciences Faculty Publications by an authorized administrator of ScholarWorks at University of Montana. For more information, please contact scholarworks@mso.umt.edu. 


\title{
OUTCROSSING RATE AND INBREEDING DEPRESSION IN THE PERENNIAL YELLOW BUSH LUPINE, LUPINUS ARBOREUS (FABACEAE) ${ }^{1}$
}

\author{
PAMela M. KitTelson ${ }^{3}$ AND John L. MARON ${ }^{2}$ \\ University of California, Bodega Marine Laboratory, P. O. Box 247, Bodega Bay, California 94923 USA
}

\begin{abstract}
Little is known about the breeding systems of perennial Lupinus species. We provide information about the breeding system of the perennial yellow bush lupine, Lupinus arboreus, specifically determining self-compatibility, outcrossing rate, and level of inbreeding depression. Flowers are self-compatible, but autonomous self-fertilization rarely occurs; thus selfed seed are a product of facilitated selfing. Based on four isozyme loci from 34 maternal progeny arrays of seeds we estimated an outcrossing rate of 0.78 . However, when we accounted for differential maturation of selfed seeds, the outcrossing rate at fertilization was lower, $\sim 0.64$. Fitness and inbreeding depression of 11 selfed and outcrossed families were measured at four stages: seed maturation, seedling emergence, seedling survivorship, and growth at 12 wk. Cumulative inbreeding depression across all four life stages averaged 0.59, although variation existed between families for the magnitude of inbreeding depression. Inbreeding depression was not manifest uniformly across all four life stages. Outcrossed flowers produced twice as many seeds as selfed flowers, but the mean performance of selfed and outcrossed progeny was not different for emergence, seedling survivorship, and size at $12 \mathrm{wk}$. Counter to assumptions about this species, L. arboreus is both self-compatible and outcrosses $\sim 78 \%$ of the time.
\end{abstract}

Key words: breeding system traits; cumulative fitness; inbreeding depression; isozymes; Lupinus; mean fitness; mixed mating system; outcrossing rate.

Plant breeding systems, in a broad sense, represent the sum of sexual characteristics that directly influence the genetic composition of subsequent generations (Wyatt, 1983). Breeding system characteristics, such as flower phenology, self-compatibility, and the mating system (narrowly defined here as the outcrossing rate) can dramatically influence the amount and distribution of genetic variation within populations (Loveless and Hamrick, 1984; Hamrick and Godt, 1989). For example, genetic subdivision can result from high rates of autofertility, self-pollination, or restricted pollinator movement (Allard, Jain, and Workman, 1968; Levin and Kerster, 1974). Alternatively, self-incompatibility or even a low frequency of outcrossing can prevent population subdivision, especially when pollen carryover is high or distant matings occur (Schaal, 1980; Slatkin, 1985; Hartl, 1988). Thus, determining the proportion of outcrossed and selfed progeny and the level of inbreeding depression can help interpret the genetic architecture of a population.

The proportion of outcrossing and selfing in a population depends, in part, on self-incompatibility mecha-

\footnotetext{
${ }^{1}$ Manuscript received 6 October 1998; revision accepted 2 September 1999.

The authors thank Dennis Hedgecock for use of his allozyme laboratory; Susan Harrison for use of tent cages; Julie Combs and Mary Greaves for field assistance; Keith Karoly, Michael Mesler, Kevin Rice, Maureen Stanton, Donald Strong, and two anonymous reviewers for their comments on the manuscript. This research was funded by grants to PMK from The Bodega Field Conference, U. C. Intercampus Research Travel Grant, and the Center for Population Biology at U. C. Davis, and JLM was supported while a post-doc by NSF grant DEB9508546 (to S. Harrison) and by NSF grant DEB-9726551 (to JLM).

${ }^{2}$ Current address: Botany Department, University of Washington, Box 355325, Seattle, Washington 98195 USA.

${ }^{3}$ Author for correspondence, current address: Department of Biology, Gustavus Adolphus College, 800 W. College Avenue, St. Peter, Minnesota 56082-1498 USA (e-mail: pkittels@ gac.edu; 507-933-7331).
}

nisms, floral development, and pollinator behavior. For self-compatible species, temporal separation of male and female reproductive phases increases the probability that outcrossing occurs (Wyatt, 1983; Richards, 1986). However, if pollen is proximal to the stigma and the stigma is receptive when the pollen is viable, then autonomous selfing (sensu Lloyd and Schoen, 1992) may occur frequently. Additionally, facilitated selfing may be high in plants with many inflorescences and where both female and male phases are mature because pollinators may forage longer among flowers of the same plant (Handel, 1985; Harder and Barrett, 1995).

Because high levels of selfing in a xenogamous species could lead to inbreeding depression, any floral trait that maintains outcrossing is likely to be advantageous (Lande and Schemske, 1985). Inbreeding depression can vary across life history stages (Kalisz, 1989; Dudash, 1990; Husband and Schemske, 1996), and the population impacts of inbreeding depression may vary depending on which life history stage is most negatively affected. Selfed genotypes that experience inbreeding depression could influence population dynamics through differential changes in seed bank input, recruitment, fecundity, or tolerance to herbivores (Hamilton and Mitchell-Olds, 1994). Identifying the life history stage most affected by inbreeding depression can aid in the interpretation of a population's demographic patterns. Additionally, empirical studies of outcrossing rates and inbreeding depression can be used to evaluate the predictions of mixed-mating models and the evolutionary trajectory of the species.

Despite numerous studies on the mating system of annual legumes, few studies have examined levels of selfcompatibility, the outcrossing rate, and level of inbreeding depression in perennial lupines. Legumes offer an interesting opportunity to evaluate how self-compatibili- 
ty, the outcrossing rate, and inbreeding depression interact; many annual members of this group appear to reproduce through a combination of selfing and outcrossing (Dunn, 1956; Fryxell, 1957; Harding, Mankinen, and Elliott, 1974; Schaal and Leverich, 1980; Faluyi and Williams, 1981; Horovitz and Harding, 1983; Pazy, 1984; Juncosa and Webster, 1989; Karoly, 1992). Moreover, even within a species, annual lupines experience variation in outcrossing rates across geographical and environmental gradients (Harding and Barnes, 1977; Horovitz and Harding, 1983; Pazy, 1984). Generalizations about the genus Lupinus presume that most annuals are self-compatible while perennial lupines are self-incompatible (Fryxell, 1957; Juncosa and Webster, 1989). However, East (1940) noted that self-sterility is rare in the papilionoid legumes. If perennial lupines are self-compatible, some species may be highly selfing if the stigma and anthers lie in close proximity and if pollen is viable when the stigma is receptive. Moreover, selfing may be high in species such as bush lupine because they produce large floral displays (Handel, 1985; Hessing, 1988; Harder and Barrett, 1995). However, even in species with large floral displays, temporal separation of male and female stages such as protandry could result in a greater rate of outcrossing (Thomson and Barrett, 1981).

Along the California coast, the perennial yellow bush lupine, Lupinus arboreus, has been the subject of numerous population-level studies (Davidson, 1975; Harrison and Karban, 1986; Bentley and Johnson, 1994; Strong et al., 1995; Harrison and Maron, 1995; Maron and Connors, 1996; Maron, 1997; Maron and Simms, 1997; Maron, 1998). At our study site, in the Bodega Marine Reserve (BMR), some yellow bush lupine stands undergo dramatic population fluctuations, while others appear more stable (Strong et al., 1995). Heavy insect herbivory appears partially responsible for large fluctuations in lupine cover, but the picture is complex because the influence of consumers on plant demography differs across stands (Strong et al., 1995), across habitats (Maron and Simms, 1997), and between years (Maron, 1998). An important but unanswered question in our system concerns the extent to which the demographic or population dynamic patterns exhibited by bush lupine are influenced by breeding system characteristics and inbreeding depression. Beyond anecdotal reports and expectations of self-incompatibility, no data have been published on selfcompatibility in L. arboreus, its outcrossing rate, or magnitude of inbreeding depression.

Here we report on details of the breeding system for L. arboreus. We ask whether $L$. arboreus is self-compatible and determine how selfed vs. outcrossed pollination treatments affect fruit and seed production. Using allozyme data, we estimate an outcrossing rate. We then examine the level of inbreeding depression by testing the performance of selfed and outcrossed progeny across four life stages to determine the magnitude and timing of inbreeding depression.

\section{MATERIALS AND METHODS}

Yellow bush lupine floral biology - Lupinus arboreus is a fast-growing, $\mathrm{N}$-fixing evergreen shrub, common to sandy soils along the California coast where it grows in grasslands and dunes. At our study site, in the Bodega Marine Reserve (BMR), Sonoma County, California, $L$. arboreus is a dominant species, covering extensive areas of grassland and scattered less densely throughout dunes. For a complete site description see Barbour et al. (1973). Most individuals flower in their second spring, when they produce numerous, yellow racemes (mean \pm $1 \mathrm{SD}=260 \pm 30$ racemes; Maron, unpublished data) from late April until July. Inflorescences mature acropetally; a whorl of 4-6 hermaphroditic flowers opens along the raceme every $2-3 \mathrm{~d}$. The combination of numerous racemes and $8-16$ open flowers/raceme results in the presence of hundreds of fertile flowers per day on each shrub. Individual flowers are protandrous; anthers dehisce viable pollen 1-2 d before stigmas become receptive (Kittelson, 1998). However, the potential for autonomous and facilitated selfing does exist because if any pollen remains in the flower it is still viable when the stigma becomes receptive (Kittelson, 1998).

In lupine flowers, when the tips of the wing and keel petals are pressed down, a mass of pollen is extruded and the stigma is revealed. As pressure eases, the stigma re-encloses in the keel. We define the movement of the wing and keel petals relative to the stigma as tripping. Tripping generally occurs when pollinators visit the flower or when the flower brushes up against other objects.

Yellow bush lupines, which do not produce nectar, are pollinated primarily by honey bees, Apis mellifera, and bumble bees, Bombus vosnesenskii (Barbour et al., 1973; Davidson, 1975). Both species of bees visit lupine more frequently in sunny, relatively calm weather vs. windy or foggy days (Kittelson, 1998). In addition, ants, thrips, small dipterans, lepidopteran larvae (Geometridae), and flower beetles are often found in the lupine flowers. These small insects have been observed covered with pollen and therefore may transfer pollen within and between flowers of the same bush (Kittelson and Maron, unpublished data). Unlike other lupines (Wainwright, 1978; Gori, 1989), there is no discernible color change after pollination. Fruits begin to elongate within $2 \mathrm{wk}$ of pollination and the dry brown pods begin to dehisce 5-7 wk later (from early July through September).

Self-compatibility and modes of pollination-We designed a total of seven treatments to determine whether $L$. arboreus is self-compatible, whether insect visitation increases fruit set, and whether seed set differs when flowers are selfed or outcrossed. Five treatments required that the plants be caged (treatments $1-5$ ). We built mesh pollinator exclosure tents around 11 plants prior to inflorescence maturation in April 1995. Pollinator exclosure tents were 1-m cubes constructed of white polyester tent-window fabric attached to a PVC (polyvinyl chloride) frame that was placed over shrubs. Prior to caging, plants were sprayed with the insecticide Sevin to kill any insects that could transfer pollen. For the remaining two treatments, 6 and 7, we marked eight bushes that remained uncovered; these plants were similar in size and phenology to covered plants. Treatments $1-5$ were performed on each of the 11 caged plants, while treatments 6 and 7 were performed on each of the eight uncaged plants. We marked five replicate inflorescences for each treatment per plant. We pollinated all flowers on each raceme to control for temporal and position effects.

Treatment 1 flowers remained unmanipulated to test for autonomous selfing (sensu Lloyd and Schoen, 1992) whereby the flower becomes pollinated without insect visitation (also called autofertility). Treatment 2 tested whether fruit set increased when we simulated insect visitation (= facilitated self-pollination); the pollen mass contacted the stigma when the keel was pushed downward. Treatment 3 tested whether the plant is capable of geitonogamous self-pollination. For this type of selfpollination, we caged and removed stamens from flowers (emasculation) and then applied pollen collected from the same bush. For treatment 4, controlled outcrosses were made by pollinating the caged, emasculated flowers with pollen collected from 14 donors. Treatment 5 served as a control to determine whether our emasculation technique inadvertently pollinated the flowers. Pollen used for cross-pollinations was collected $17-70 \mathrm{~m}$ away from pollen recipients. 
To ensure fruit and seed set among hand-pollinated flowers, we determined the approximate timing of stigma receptivity and pollen viability (Kittelson, 1998). For each treatment that included emasculation (treatments 3-6), the stamens and keel petals were removed from each flower on a whorl $24 \mathrm{~h}$ prior to anthesis. We brushed any pollen from the stigma following emasculation. After emasculation, the gynoecium was re-enclosed within the wing petals. For geitonogamous selfed, and outcrossed treatments ( 3 and 4 ), we collected pollen from the appropriate donors $\sim 1-2 \mathrm{~d}$ after the stamens were removed. We always used pollen of similar age, and we attempted to use equivalent pollen loads across all treatments for each day. We applied the pollen to stigmas using a wooden stick with a small piece of velour fabric glued on the end. For treatment 4, one flower per whorl was emasculated, but not pollinated to serve as a control for inadvertent pollination. If that flower set seed, we did not include information about seed set or collect seeds from treatment flowers on that whorl.

The first uncaged treatment, 6, determined whether emasculation altered or interfered with natural pollination. The last uncaged treatment, 7 , experienced open pollination.

Once fruits developed, we tied nylon bags around each inflorescence to prevent seeds from being lost due to explosive dehiscence. We collected fully mature fruits from late July to September 1995 and counted the total number of seeds per fruit. Developed seeds were fully round and covered with a hard, brownish to black seed coat. Between 97 and $99 \%$ of developed seeds germinated when scarified $(N=500)$.

Flower number per inflorescence did not differ across our treatments (Kruskal-Wallis ANOVA on ranks, $P=0.07$ ). For each treatment, we totaled the number of fruits per flower across the five inflorescences on a given plant. Therefore, our unit of observation for all treatments was the mean number of fruits per flower per plant (treatments $1-5, N=$ $11 ; N=8$ for treatments 6 and 7). We tested for differences among treatments using Kruskal-Wallis ANOVA on ranks. All pairwise comparisons were made using Dunn's method and controlled for multiple comparisons (SYSTAT, 1997).

Mating system - We determined the outcrossing rate and mating system for L. arboreus using horizontal starch electrophoresis. We collected seeds from a lupine population $\sim 0.5 \mathrm{~km}^{2}$ in area at BMR. Ten seeds from each of 34 maternal families were ground in a simple 0.1 mol/L Tris-HCl (pH 8), PVP-40, and mercaptoethanol buffer (K. Karoly, unpublished protocol). Filtrate was immediately absorbed onto 2 $\times 5 \mathrm{~mm}$ Whatman filter paper wicks for separation on a $12 \%$ lithium hydroxide gel and buffer system, $\mathrm{pH}=8.1 / 8.4$ (Werth, 1985). Gels were run for $7 \mathrm{~h}$ at $50 \mathrm{~mA}$ and $200 \mathrm{~V}$. We stained for five polymorphic loci that exhibited consistently clear banding patterns: Adh-1 and Adh2 (alcohol dehydrogenase; E.C. [Enzyme Commission] 1.1.1.1); Est (esterase; E.C. 3.1.1) (enzyme recipes modified from Wendel and Weeden, 1990), and Tap-2 and Tap-3 (tri-amino peptidase, E.C. 3.4; enzyme recipe from Hedgecock, unpublished protocol). Isozyme designations refer to the relative positions of bands on a gel, with the lowest number corresponding to the most anodally migrating locus. Mendelian segregation of all loci was verified using arrays of selfed progeny. Since our caged treatments indicated that $L$. arboreus reproduces through a mixture of selfing and outcrossing, we calculated the mean single $\left(t_{s}\right)$ and multilocus $\left(t_{m}\right)$ outcrossing rate using Ritland's (1990) mixed-mating model program (MLT). Because the model allows for only three alleles, we created a synthetic allele combining the relatively rare third and fourth alleles in Est and Adh-2 (Murawski and Bawa, 1994; Husband and Schemske, 1995). Maternal genotypes, the proportion of offspring derived from outcrossing, and the frequencies of alleles in pollen and ovule pools were inferred using a maximum likelihood procedure. Standard errors for $t_{s}$ and $t_{m}$ were calculated based on the 600 bootstraps for each of the 34 progeny arrays. We found $95 \%$ confidence intervals for $t_{m}$ and $t_{s}$ using the percentile method (Efron and Gong, 1983). We used these confidence intervals to determine whether $t_{m}$ was significantly different from unity $\left(t_{m}=1\right)$. A measure of the inbreeding coefficient,
$F$, was estimated by using inferred maternal genotypes (Ritland, 1990); a significant $F$ indicates inbreeding (Wright, 1922). The potential for biparental inbreeding was examined by ranking bootstrap confidence intervals for the difference between $t_{m}$ and $t_{s}$ to determine whether the values were significantly different from zero.

To adjust for inbreeding depression that may have occurred prior to fruit and seed development, we calculated the selfing rate at fertilization $(r)$, as, $r=r_{m} /(1-\delta)+r_{m} \delta$, where $r_{m}=1-t_{m}$ and $\delta$ is the average inbreeding depression measured at seed maturation. Inbreeding depression measured at seed set was calculated as, $\delta=1-\left(S_{S} / S_{o}\right)$, where $S_{s}$ $=$ seed set from selfed plants and $S_{o}=$ seed set from outcrossed plants (Maki, 1993).

Inbreeding depression-To determine whether there was any evidence for post-zygotic inbreeding depression, we compared the fitness of outcrossed and selfed progeny at four stages: seed set, seedling emergence, seedling survivorship and seedling size at $12 \mathrm{wk}$. We counted the number of seeds per fruit for $10-11$ fruits.treatment ${ }^{-1}$. plant $^{-1}$ by randomly selecting 2-3 fruits from each of the five marked inflorescences $\cdot$ treatment ${ }^{-1} \cdot$ bush $^{-1}$. We collected $8-11$ (mean \pm 1 SD $=9.9 \pm$ $0.64)$ developed seeds from self-fertilized or outcrossed inflorescences on each of the 11 caged plants (treatments 4 and 5). We scarified seeds with a razor blade and planted each seed in an individual plastic cylinder (diameter $=38 \mathrm{~mm}$, height $=135 \mathrm{~mm}$ ) containing sterile potting soil. Pots were placed in racks, $\sim 2 \mathrm{~cm}$ apart. Plants were grown in a greenhouse and watered two times daily. After 4 wk, we recorded emergence rates. In April 1998, we planted 5-10 (mean \pm 1 SD $=9.3 \pm$ 1.4) seedlings from each parent in a $10 \times 25 \mathrm{~m}$ mowed plot located in a grassland where lupines are naturally abundant. Seedlings were planted at $1-\mathrm{m}$ intervals in randomly assigned locations within this garden. We measured seedling survival and height after $12 \mathrm{wk}$.

We calculated overall mean fitness of selfed and outcrossed progeny from the means of 11 maternal families at each stage. Cumulative fitness for selfed and outcrossed seeds was the product of 11 maternal family mean fitnesses at each stage: number of seeds set, proportion of emergent seedlings, proportion of seedlings surviving and seedling height $(\mathrm{cm})$. Inbreeding depression $(\delta)$ was calculated following Husband and Schemske (1995) where $\delta=1-\left(w_{s} / w_{o}\right), w_{s}$ is the mean fitness of selfed progeny, and $w_{o}$ is the mean fitness of outcrossed progeny. These calculations estimate the cost of producing selfed offspring by giving equal weight to each family, regardless of variability in initial or final sample sizes.

We compared mean and cumulative fitnesses of selfed and outcrossed progeny at each stage with paired $t$ tests (paired within maternal family). To meet assumptions of our tests, proportion of seedling emergence and survivorship were arcsine transformed. Seed number and seedling size were $\log$ transformed. Individual values for cumulative fitness were calculated by taking the square root of the arcsine values for seedling emergence and seedling survivorship and multiplying them by the log of seed number and size. We used a mixed-model ANOVA to examine the effects of pollination treatment (fixed effect) and family (random effect) on seed set, size at $12 \mathrm{wk}$, and cumulative fitness. We used logistic regression to determine the individual and interactive effects of pollination treatment and family on seedling emergence and survival. We performed among-family correlations for seed number and cumulative fitness using Spearman rank correlations. All statistics were performed with SYSTAT (1997).

\section{RESULTS}

Self-compatibility and modes of pollination-Lupine flowers are self-compatible, but rarely set fruit as a result of autonomous selfing (only $2 \%$ of unmanipulated flowers developed into fruits; Table 1). Flowers in which the keel was pressed downward, but did not have self pollen rubbed onto the stigma, developed fruit with intermediate 
TABLE 1. The mean number of fruits per flower and seeds per fruit $( \pm$ $1 \mathrm{SE}$ ) developing for each pollination treatment (treatments $1-5, N$ $=11 ; N=8$ for treatments 6 and 7). Treatments with the same letter were not statistically different from one another, while treatments with different subscripts were significantly different (Kruskal-Wallis ANOVA on ranks; $P<0.001$ )

\begin{tabular}{|c|c|c|}
\hline Treatment and purpose & $\begin{array}{l}\text { Mean no. } \\
\text { fruits/flower }\end{array}$ & $\begin{array}{l}\text { Mean no. } \\
\text { seeds/fruit }\end{array}$ \\
\hline $\begin{array}{l}\text { 1. Caged, unmanipulated-tests for } \\
\text { delayed autopollination and self- } \\
\text { compatibility }\end{array}$ & $0.02 \pm 0.11^{\mathrm{c}}$ & $2.22 \pm 0.48^{a}$ \\
\hline $\begin{array}{l}\text { 2. Caged, tripped-tests for self-com- } \\
\text { patibility and if fruit set increases } \\
\text { when insect visitation is simulated. }\end{array}$ & $0.06 \pm 0.10^{\mathrm{b}}$ & $2.56 \pm 0.13^{\mathrm{a}}$ \\
\hline $\begin{array}{l}\text { 3. Caged, emasculated, geitonoga- } \\
\text { mous selfing. }\end{array}$ & $0.08 \pm 0.26^{\mathrm{a}}$ & $2.42 \pm 0.22^{\mathrm{a}}$ \\
\hline $\begin{array}{l}\text { 4. Caged, emasculated outcrossed- } \\
\text { provides basis for judging degree } \\
\text { of self-compatibility. }\end{array}$ & $0.13 \pm 0.21^{\mathrm{a}}$ & $4.25 \pm 0.14^{\mathrm{b}}$ \\
\hline $\begin{array}{l}\text { 5. Caged, emasculated-a control to } \\
\text { see whether emasculation inadver- } \\
\text { tently pollinates flowers. }\end{array}$ & $<0.01 \pm 0.09^{c}$ & $2.25 \pm 0.75^{\mathrm{a}}$ \\
\hline $\begin{array}{l}\text { 6. Emasculated, open-pollination- }- \\
\text { tests whether emasculation inter- } \\
\text { feres with natural pollination. }\end{array}$ & $0.12 \pm 0.25^{a}$ & $4.06 \pm 0.18^{\mathrm{b}}$ \\
\hline $\begin{array}{l}\text { 7. Open-pollination-provides a base- } \\
\text { line for natural fruit and seed set } \\
\text { production. }\end{array}$ & $0.11 \pm 0.35^{\mathrm{a}}$ & $4.37 \pm 0.16^{\mathrm{b}}$ \\
\hline
\end{tabular}

probability, resulting in $\sim 6 \%$ of the flowers developing fruit (Table 1). Fruits resulting from geitonogamous selfpollination and outcrossing produced the highest percentage of fruits per flower, between 8 and $13 \%$ (Table 1). Fruit set of selfed vs. outcrossed flowers are equivalent, but outcrossed flowers produced approximately twice as many seeds as selfed flowers (Table 1). The mean number of fruits produced varied among pollination treatments (Table 1; Kruskal-Wallis ANOVA on ranks, $P$ $<0.001)$.

Very few fruits developed on caged, emasculated control shrubs $(<1 \%$; treatment 5$)$. The presence of a few fruits could be a result of two phenomena: apomixis or our failure to remove all the pollen from the flower or stigma after emasculation. It is highly unlikely that apomixis accounts for this result because there is no evidence for this in lupines (Richards, 1986). More likely, we accidentally pollinated some flowers while emasculating them. This possibility is further supported by comparing the number of control flowers that set fruit among the controlled outcrossed treatment. Approximately one out of 200 emasculated, control flowers set fruit, suggesting that emasculation may have inadvertently resulted in fertilization.

We also recorded the number of aborted seeds in $L$. arboreus. Aborted seeds generally are larger than unfertilized ovules, but are smaller than mature, viable seeds (Kittelson, unpublished data). There was a mean of 1.92 \pm 0.46 aborted seed in selfed fruits and a mean of 0.43 \pm 0.18 aborted seed in outcrossed fruits.

Mating system - Lupinus arboreus has a mixed mating system with $\sim 22 \%$ of the seeds produced from selfing. The mean single locus outcrossing rate $\left(t_{s}\right)$ for five loci was 0.718 , while the multilocus outcrossing rate $\left(t_{m}\right)$ was 0.779 . The value of $t_{m}$ was significantly different from unity $\left(t_{m}=1\right)$ because there was no overlap in the $95 \%$ confidence intervals (range of $t_{m}$ within $95 \%$ confidence intervals $=0.730-0.827$ ). By incorporating a measure of inbreeding depression at seed maturation, we calculated a selfing rate at fertilization $(r)$ of 0.36 . In other words, at the time of fertilization, we estimate that $36 \%$ of the ovules were selfed.

Our estimate of the inbreeding coefficient $(F)$ was 0.001 and was not different from zero. However, we detected some evidence for biparental inbreeding, because there was always a positive difference between average $t_{s}$ and $t_{m}$ values across the 600 bootstraps (average difference $=0.061$; difference within $95 \%$ confidence intervals $=0.027-0.093 ; 95 \%$ confidence intervals do not overlap with zero). Approximately $8 \%$ of the selfing in the population can be attributed to biparental inbreeding (Shaw and Allard, 1982). The frequency of heterozygotes exceeded that expected by the mating system because the inbreeding coefficient, $F$, was not significantly different from zero and was less than the equilibrium inbreeding coefficient estimated from selfing (Clegg, 1980).

Inbreeding depression-Across all four life stages, selfed progeny exhibited significantly reduced cumulative fitness compared to outcrossed progeny $(N=11$, paired $t$ test, $t=-5.3, P<0.001)$. Cumulative inbreeding depression $(\delta)$ across all four life stages averaged 0.59. Inbreeding depression, however, was not uniformly manifest at all life stages. Inbreeding depression was greatest between fertilization and seed maturation $(\delta=0.49)$ with outcrossed flowers producing approximately twice as many seeds as selfed flowers (Tables 1-3). Mean fitnesses for selfed and outcrossed progeny were similar for emergence, seedling survival, and seedling size (paired $t$ test, $t=-0.58 ; t=-0.29 ; t=-2.69 ; P>0.05$ for emergence, seedling survival, and seedling size respectively).

Outcrossed flowers produced significantly more seed than did selfed flowers (Table 3). Seed production, however, was unaffected by maternal family or a family by pollination treatment interaction (Table 3). Pollination treatment, maternal family, and the interaction of these factors had no significant effect on seedling emergence (logistic regression, $P>0.05$ ), seedling size at $12 \mathrm{wk}$ (Table 3), or seedling survival (logistic regression, $P>$ $0.05)$. There was less variation among families in seedling emergence (Fig. 1a) than there was for the proportion of seedlings surviving after $12 \mathrm{wk}$ (Fig. 1b). Cumulative fitness was significantly influenced by pollination treatment, maternal family, and the maternal family by treatment interaction (Table 3). Thus, maternal families vary in fitness and the magnitude of inbreeding depression varies among maternal families.

The frequency distributions of cumulative mean fitness for selfed and outcrossed families were different from one another (Kolmogorov-Smirnov test, $P<0.05$ ). This variation in fitness affected values for inbreeding depression; $\delta$ across the 11 maternal families ranged between 0.15 and 0.81 (Table 2). All selfed families expressed lower cumulative fitness than outcrossed progeny, thus inbreeding depression exists for each of the maternal families (Fig. 2). However, there were a few stages where selfed progeny performed better than outcrossed. The number of maternal families where selfed progeny fitness 
TABLE 2. Performance of selfed and outcrossed progeny at four life history stages: seed maturation, seedling emergence, seedling survival, and size. Mean fitness ( \pm 1 SD) at each stage was calculated by averaging the mean fitness values derived for each of 11 maternal families. This weighs each family equally even if they diverge in number of progeny. Cumulative fitness was figured by the product of the mean fitness at each stage (percentages were converted to proportions first). Inbreeding depression was calculated by subtracting the ratio of selfed fitness over outcrossed fitness from one.

\begin{tabular}{lccc}
\hline \hline \multicolumn{1}{c}{ Stage } & Selfed & Outcrossed & $\delta$ (range) \\
\hline Seed set (no./fruit) & $2.36(0.42)$ & $4.64(0.81)$ & $0.49(0.25$ to 0.71$)$ \\
Seedling emergence $(\%)$ & $96.4(5.00)$ & $97.8(5.00)$ & $0.02(-0.18$ to 0.10$)$ \\
Survival to 12 wk $(\%)$ & $70.2(13.8)$ & $77.5(12.0)$ & $0.10(-0.55$ to 0.44$)$ \\
Size at 12 wk $(\mathrm{cm})$ & $13.2(4.15)$ & $14.5(4.62)$ & $0.09(-0.14$ to 0.27$)$ \\
Cumulative means & $21.1(12.6)$ & $51.3(17.3)$ & $0.59(0.15$ to 0.81$)$ \\
\hline
\end{tabular}

was greater than outcrossed totaled zero at seed set, two at seedling emergence (Fig. 1a), two at seedling survival (Fig. 1b), and three for when seedlings were measured.

Cumulative fitnesses of selfed vs. outcrossed progeny were not significantly correlated among families (Fig. 2, $r=0.23, P>0.05)$. But, the positive $r$ value and the trend were indicative of inbreeding depression among all families. Lack of significance is due partly to low sample size $(N=11)$. Likewise, average seed number for selfed and outcrossed fruit was not correlated among families $(r=-0.03, P>0.05)$.

\section{DISCUSSION}

Our outcrossing estimates show that L. arboreus produces a mixture of selfed and outcrossed seeds. Experimental pollination treatments in natural populations also support that L. arboreus is self-compatible, although autonomous self-pollination rarely occurs. We found that selfed fruit and seed usually develop only after the keel has been physically manipulated, indicating that self-pollination is mediated by insect visitors. Therefore, for $L$. arboreus, the majority of selfed seeds in natural populations are a result of facilitated self-pollination. Even though similar numbers of fruits develop in selfed and outcrossed treatments only one-half of the seeds mature in selfed fruit. Differential seed maturation is due to inbreeding depression acting between fertilization and seed maturation.

At the onset of our study, we hypothesized that $L$. arboreus might have a high selfing rate (in the 50-70\% range). This hypothesis was based on observations of bees visiting multiple flowers on the same shrub (Kittelson and Maron, unpublished data) and the fact that we often found numerous small insects within individual flowers, which we assumed might facilitate selfing (see Baker and Cruden, 1991). Moreover, we assumed that since fog and extreme wind are common during the spring flowering period, opportunities for outcrossing by flying insects might be limited and that selfing may increase in part because of poor environmental conditions (Schoen and Brown, 1991; Lloyd and Schoen, 1992). However, despite these possibilities, we found that the
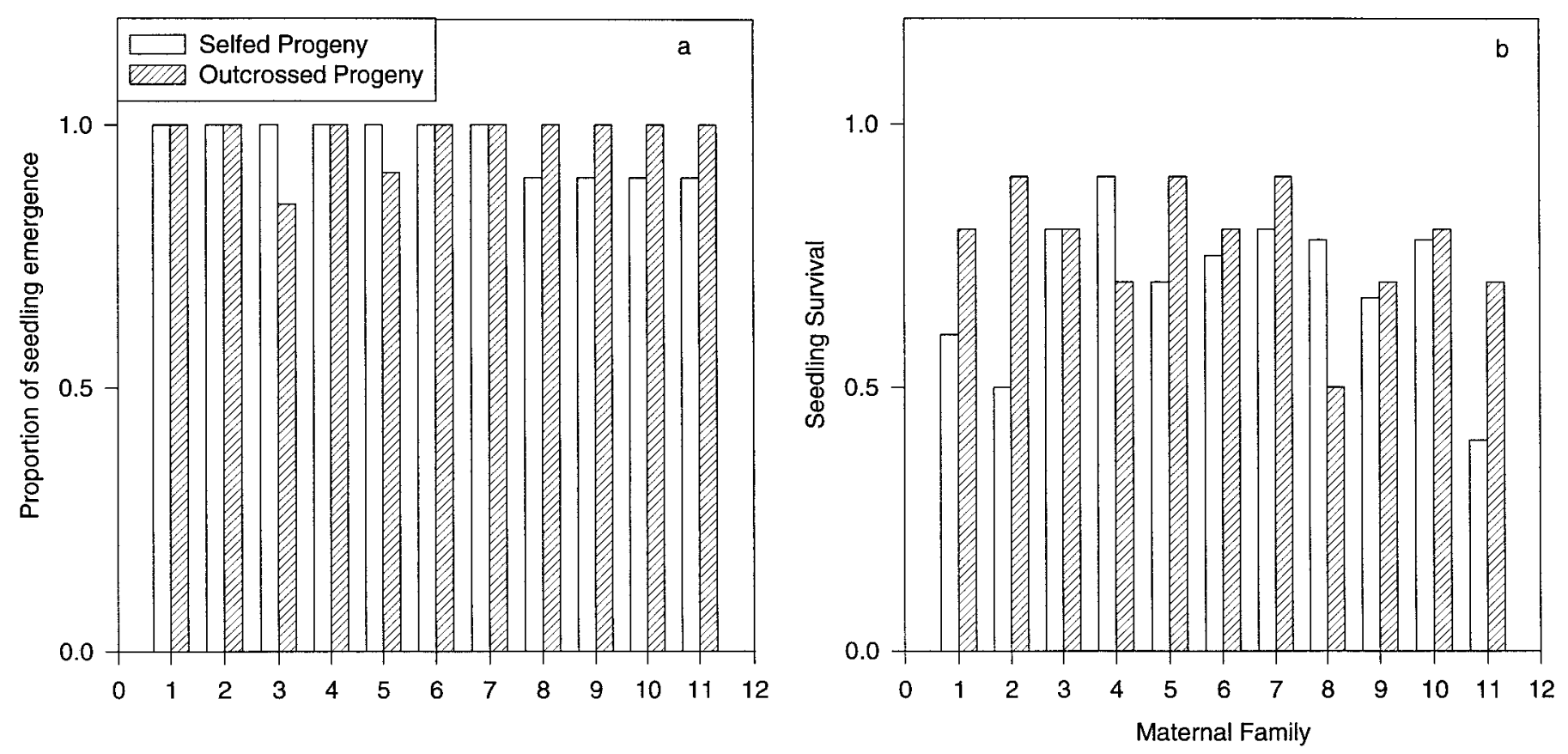

Fig. 1. Distributions of (a) Lupinus arboreus seedling emergence $\left(N=8-10\right.$ seeds.family ${ }^{-1} \cdot$ treatment $\left.^{-1}\right)$, and (b) survival for each of the 11 selfed and outcrossed maternal families $\left(N=8-10\right.$ seedlings $\cdot$ family $^{-1} \cdot$ treatment $\left.^{-1}\right)$. 
TABLE 3. Effects of selfed and outcrossed pollination treatment, maternal family, and treatment $\times$ family interaction on the log of seed number, size, and cumulative fitness for L. arboreus as determined by a mixed-model ANOVA.

\begin{tabular}{llrrc}
\hline \hline & \multicolumn{1}{c}{ Source of variation } & df & \multicolumn{1}{c}{ MS } & \multicolumn{1}{c}{$F$} \\
\hline Seed number & Pollination treatment & 1 & 17.26 & $297.9 * * *$ \\
& Maternal Family & 10 & 0.21 & 0.94 \\
& Treatment $\times$ Family & 10 & 0.06 & 0.25 \\
& Error & 195 & 0.23 & \\
Size at 12 wk & Pollination treatment & 1 & 0.04 & 4.55 \\
& Maternal Family & 10 & 0.03 & 0.94 \\
& Treatment X Family & 10 & 0.01 & \\
& Error & 129 & 0.03 & \\
& Pollination treatment & 1 & 368.5 & $29.98 * * *$ \\
& Maternal Family & 10 & 19.9 & $3.6 * * *$ \\
& Treatment $\times$ Family & 10 & 12.3 & $2.2 * * *$ \\
& Error & 189 & 5.6 & \\
\hline
\end{tabular}

$* * * P<0.001$

selfing rate at fertilization (36\%) was lower than we hypothesized. Similarly, Godt and Hamrick (1991) found that another legume, Lathyrus latifolius, had an apparent selfing rate of 0.37 , which they attributed to bumble bee foraging behavior and multiple racemes on plants.

Our low rate of autofertility (= autogamous selfing) is consistent with a survey of the literature done by Lloyd and Schoen (1992); they found that members of the Fabaceae tend to have low autofertility indices, which are probably due to the specialized pollination mechanisms present in legumes. The paucity of autogamy observed for yellow bush lupine is probably a result of three floral features that discourage autofertility. First, the stigma may need physical stimulation to accept pollen. On geitonogamous flowers we rubbed pollen on the stigma with a fabric applicator, and this may be the reason why we saw greater fruit set on these flowers relative to unmanipulated or tripped flowers. Lord and Heslop-Harrison (1984) found that in the legume Vicia faba pollen did not germinate until the stigmatic cuticle was disrupted and lipid-rich secretions hydrated the pollen. In the highly selfing L. albus, an oily substance dissolves the stigmatic cuticle, but this secretion is absent in other lupine species (Horovitz and Harding, 1983). In natural pollinations, insects probably provide the physical pressure necessary to ensure pollination. Pazy (1984) found a significant increase in pod production of the annuals L. palaestinus and L. pilosus following depression of the keel by insects. Also, Juncosa and Webster (1989) found that pollen-hydrating secretions were accelerated after insect visitation. Second, autofertility may be limited by a temporal separation of the anthers and stigma called protandry. For $L$. arboreus, the flowers open and the anthers produce viable pollen 1-2 d before stigmas became receptive (Kittelson, 1998). Even though this developmental separation is not complete (because the stigma becomes receptive when the pollen is still viable), pollen may not be present in the flower following insect visitations. Third, a ring of rigid, peristigmatic hairs may prevent autopollination by guarding the stigma from self-pollen after the stamens dehisce pollen (Juncosa and Webster, 1989). Thus, autogamous selfing may be limited by a combination of protandry, a ring of peristigmatic hairs, and the need for a

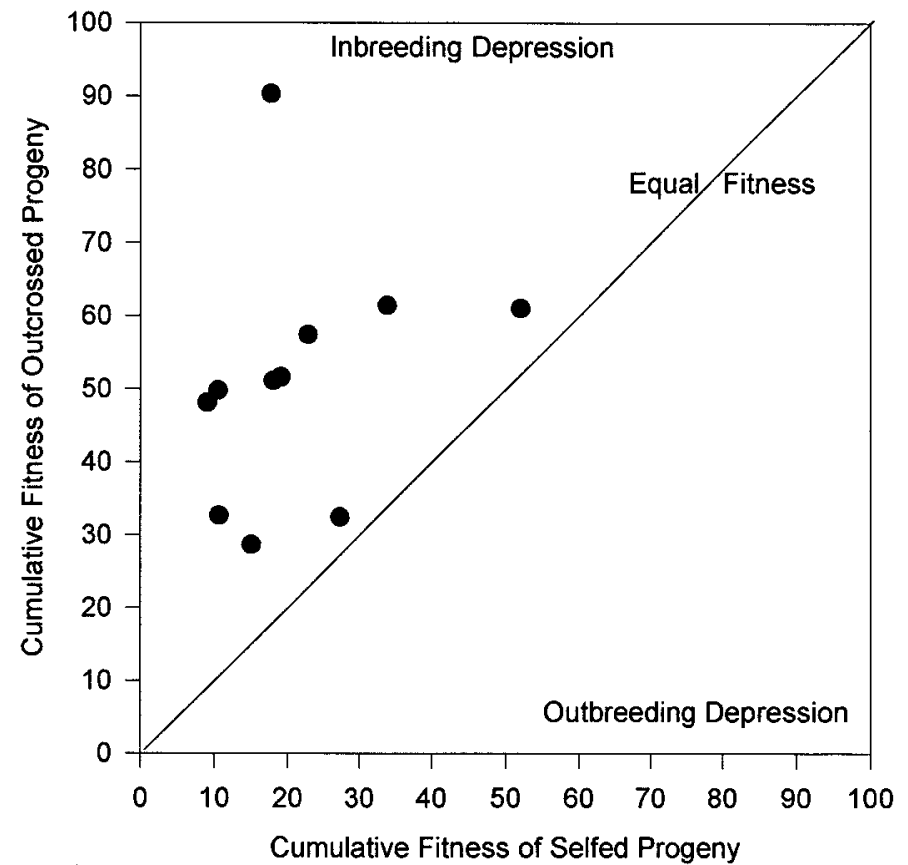

Fig. 2. Cumulative fitness values for selfed and outcrossed progeny from each maternal family of Lupinus arboreus. The diagonal line represents equal cumulative fitness for outcrossed and selfed progeny. Families plotted above the line are experiencing inbreeding depression, while families found below experience outbreeding depression. Cumulative fitness $=$ mean fitnesses for seed set $\times$ seedling emergence $\times$ survival $\times$ size.

physical mechanism to facilitate pollination. Annual lupines that are primarily outcrossed or experience mixedmating systems usually exhibit a high degree of protandry: Lupinus texenis (Schaal and Leverich, 1980), L. arizonicus (Dunn, 1956), L. sparsiflorus (Wainwright, 1978), L. luteus (Wallace, Hanson, and Decker, 1954), and L. nanus subspecies latifolius (Harding, Mankinen, and Elliott, 1974; Karoly, 1994). In contrast, annual lupines that are highly selfing tend to experience an overlap in reproductive maturity and can set seed without the keel being tripped: Lupinus bicolor (Dunn, 1956; Karoly, 1994), L. nanus (Juncosa and Webster, 1989), L. pilosus (Horovitz and Harding, 1983), L. polycarpus, and L. pachylobis (Harding, Mankinen, and Elliott, 1974). Some natural autogamous selfing may occur in yellow bush lupine as a result of frequent windy conditions that cause flowers to move against the shrub thereby forcing pollen into contact with the stigma.

Reductions in seed set after pollination could mean that $L$. arboreus either is partially self-incompatible at prezygotic stages or suffers from inbreeding depression. Self-incompatibility is a result of maternal tissue/pollen interactions and typically occurs at the surface of the stigma or in the style. Also, reductions in selfed seed could be due to differences in pollen quality because when mixed pollen loads are deposited onto stigmas, self pollen can grow more slowly than an outcrossed pollen source (Stephenson and Winsor, 1986; Weller and Ornduff, 1991; Lloyd and Schoen, 1992). However, it remains unclear whether variation in selfed and outcrossed pollen tube growth occurs in L. arboreus. Similar numbers of 
fruits develop after selfing and outcrossing, which argues against self-incompatibility being the sole cause of reduced seed set in selfed flowers. Also, given that we often detected aborted zygotes and that the percentage of aborted zygotes was greater in selfed than outcrossed fruit, we believe that inbreeding depression is a more likely explanation than self-incompatibility for the lowered seed production by selfed flowers. Inbreeding depression is common for flowering plants (Darwin, 1876; Schemske, 1983; Johnston, 1992; Hamilton and Mitchell-Olds, 1994; Husband and Schemske, 1995) and often acts between fertilization and seed maturation to decrease seed set. Because our inbreeding coefficient, $F$, was not significantly different from zero, our mating system analysis suggests that selection for heterozygotes, or against inbred genotypes occurs for L. arboreus. Selfed genotypes could be selected against because the embryo experiences genetic load, where one or more combinations of lethal or deleterious homozygous alleles are present. Also, outcrossed progeny may experience overdominance, where there is greater fitness among outcrossed seeds because a higher proportion of heterozygous loci are found. Inbreeding depression caused by genetic load or overdominance typically appears after fertilization.

Lupinus arboreus expresses virtually all of the inbreeding depression we measured at seed maturation. There are no significant differences between selfed and outcrossed progeny performance at the other three life history stages we examined. Several researchers have found that levels of inbreeding depression vary across life history stages; some plants express highest values for $\delta$ at seed production (Schemske, 1983; Dudash, 1990; Weller and Ornduff, 1991; Husband and Schemske, 1995), while other researchers detect more inbreeding depression at later life history stages (see citations in Johnston, 1992; Husband and Schemske, 1996). Husband and Schemske (1996) generalized that selfers express the largest values for inbreeding depression late in the life cycle, perhaps at reproduction, while plants that are primarily outcrossers manifest more inbreeding depression early in the life cycle (e.g., at seed production). The value for inbreeding depression in L. arboreus is similar to the average for all outcrossed populations ( $\delta=0.53$ ), two times higher than all selfing species, but it is not as high as values for other long-lived woody perennials (Husband and Schemske, 1996). However, our estimations of inbreeding depression may be underestimates since we did not compare germination in natural conditions or follow traits beyond the juvenile stage.

Mating system largely influences the evolutionary dynamics of plant populations. It has been argued that inbreeding depression manifest early in life history, as is the case for L. arboreus, may be maintained if these early stages contribute little to population increases (Haldane, 1957; Mitchell-Olds and Waller, 1985). Disregarding the fitness cost at seed set, fitnesses of selfed and outcrossed progeny are similar for the juvenile life stages. Moreover, there are even some cases where selfed seed are more fit than outcrossed. This indicates that fitness costs are "paid" by the maternal bush because more selfing results in lower seed set, thus lower fitness. However, once established, selfed and outcrossed seedlings may experience similar fitnesses. In order to determine lifetime effects of inbreeding on fitness, we need data that describes growth, viability, and fecundity of selfed and outcrossed adult $L$. arboreus.

Although natural selfing rates are fairly low (0.22), $L$. arboreus still maintains a relatively moderate amount of inbreeding depression $(\delta=0.59)$. Inbreeding depression is an important selective force that can influence the evolution of mating systems (Schemske and Lande, 1985; Charlesworth and Charlesworth, 1987; Holsinger, 1991; Lloyd, 1992). Even though the evolutionary trajectory of a mating system is difficult to predict because of complex genetic and functional factors (Charlesworth, Morgan, and Charlesworth, 1990; Uyenoyama and Waller, 1991; Lloyd, 1992; Barrett and Harder, 1996), some theoretical models suggest that the mixed-mating system exhibited by $L$. arboreus should be transitory and evolve to a predominantly outcrossing system (Schemske and Lande, 1985; Lloyd, 1992). However, a mixed-mating system may be evolutionarily stable in L. arboreus for several reasons. First, mutation rates may be high enough to keep deleterious, partially recessive alleles in the population, thereby enabling the population to maintain inbreeding depression (Lande, Schemske, and Schultz, 1994). Second, selfing may be maintained because there is variation in both fitness and the magnitude of inbreeding depression (Holsinger, 1991). Third, functional factors can also cause selection for intermediate selfing rates because facilitated selfing may be an unavoidable consequence of adaptations which also promote outcrossing (Lloyd, 1992). Lastly, Holsinger (1986) suggests that if there is differential dispersal and establishment of selfed and outcrossed progeny among locally adapted subpopulations, then intermediate selfing rates can be maintained.

Given that $L$. arboreus is an insect-pollinated plant with both floral and genetic mechanisms that reduce the production of selfed seed, we expected to see little spatial population structure. Flying insects can potentially move pollen across long distances and pollen carry-over increases the probability that long distance outcrossing will occur (Schaal, 1980; Handel, 1983). Also, higher rates of outcrossing and reductions in the production of selfed seeds should prevent the formation of population subdivision at BMR. However, trends in life history traits suggest that genetically different subpopulations of $L$. arboreus do exist across a relatively small spatial scale (Kittelson, 1998). Additionally, families from some seed origins are locally adapted. However, the spatial differentiation in lupine life history traits appears to result from strong selection regimes within and among sites rather than from limitations in gene flow (Kittelson, 1998).

Based on anecdotal analyses of floral morphology, development, and display, L. arboreus was assumed to be either highly selfing or self-incompatible. Our results show that neither of these possibilities is realized; L. arboreus is a self-compatible perennial that reproduces through a mixture of selfed and outcrossed pollinations. Selfed progeny exhibit substantial inbreeding depression, expressed primarily at the seed maturation stage. Fitness costs of selfing are suffered by the maternal bush. Once lupine become established, selfed and outcrossed seedlings may experience similar fitnesses, which may contribute to the long-term maintenance of a mixed-mating system. Given the relatively low rates of selfing, neither 
the mating system or inbreeding depression should by themselves drive substantial genetic structuring of $L$. arboreus populations at our site.

\section{LITERATURE CITED}

Allard, R. W., D. K. JAIn, AND P. L. Workman. 1968. The genetics of inbreeding populations. Advances in Genetics 14: 55-131.

Barbour, M. G., R. B. Craig, R. R. Drysdale, and M. T. Ghislen. 1973. Coastal ecology of Bodega Head. University of California Press, Berkeley, California, USA.

BAKER, J. D., AND R. W. CRUDEN. 1991. Thrips-mediated self-pollination of two facultatively xenogamous wetland species. American Journal of Botany 78: 959-963.

BarretT, S. C. H., AND L. D. HARDER. 1996. Ecology and evolution of plant mating. Trends in Ecology and Evolution 11: 73-79

Bentley, B. L., AND N. D. Johnson. 1994. The impact of defoliation by a tussock moth, Orgyia vetusta, on a nitrogen-fixing legume, Lupinus arboreus. In J. L. Sprent and D. McKey [eds.], Advances in legume systematics, part 5, The nitrogen factor, 169-178. Royal Botanic Gardens, Kew, UK.

Charlesworth, D., AND B. Charlesworth. 1987. Inbreeding depression and its evolutionary consequences. Annual Review of Ecology and Systematics 18: 237-268.

- M. T. Morgan, And B. Charlesworth. 1990. Inbreeding depression, genetic load and the evolution of outcrossing rates in a multilocus system with zero linkage. Evolution 44: 1469-1489.

ClegG, M. T. 1980. Measuring plant mating systems. BioScience 30: $814-818$.

DARWIN, C. 1876. The effects of cross- and self-fertilization in the vegetable kingdom. Murray, London, UK.

DAvidson, E. D. 1975. Demography of Lupinus arboreus at Bodega Head, California. Ph.D. dissertation, University of California, Davis, California, USA.

DudAsh, M. R. 1990. Relative fitness of selfed and outcrossed progeny in a self- protandrous species, Sabatia angularis L. (Gentianaceae): a comparison of three environments. Evolution 44: 1129-1139.

DunN, D. B. 1956. The breeding systems of lupinus, group micranthi. American Midland Naturalist 55: 543-572.

EAst, E. M. 1940. The distribution of self-sterility in the flowering plants. Proceedings of the American Philosophical Society 82: 449-518.

Efron, B., AND G. Gong. 1983. A leisurely look at the bootstrap, the jackknife, and cross-validation. American Statistician 37: 36-48.

FALUYI, M. A., AND W. Williams. 1981. Studies on the breeding system in lupin species: a) self- and cross-compatibility in three European lupin species, b) percentage outcrossing in Lupinus albus. Zietschrift für Pflanzenzüchtung 87: 233-239.

FryXELl, P. A. 1957. Mode of reproduction of higher plants. Botanical Gazette 23: 135-233.

GodT, M. J. W., AND J. L. HAMricK. 1991. Estimates of outcrossing rates in Lathyrus latifolius poplations. Genome 34: 988-992.

GoRI, D. F. 1989. Floral color change in Lupinus argenteus (Fabaceae): why should advertise the location of unrewarding flowers to pollinators? Evolution 43: 870-881.

Haldane, J. B. S. 1957. The cost of natural selection. Journal Genetics 55: 511-524.

Hamilton, M. B., And T. Mitchell-Olds. 1994. The mating system and relative performance of selfed and outcrossed progeny in $A r$ abis fecunda (Brassicaceae). American Journal of Botany 8: 1252 1256.

HAMrick, J. L., AND M. J. W. GodT. 1989. Allozyme diversity in plant species. In A. D. H. Brown, M. T. Clegg, A. L. Kahler, and B. S. Weir [eds.], Population genetic resources in crop improvement, 4446. Sinauer, Sunderland, Massachusetts, USA.

HANDEL, S. N. 1983. Contrasting gene flow patterns and genetic subdivision in adjacent populations of Cucumis sativus (Cucurbitaceae). Evolution 37: 760-771.

- 1985. The intrusion of clonal growth patterns of plant breeding systems. American Naturalist 125: 367-384.

Harder, L. D., And S. C. H. BarretT. 1995. Mating cost of large floral displays in hermaphrodite plants, Nature 373: 512-515.

Harding, J., And K. Barnes. 1977. Genetics of Lupinus. X. Genetic variability, heterozygosity and outcrossing in colonial populations of L. succulentus. Evolution 31: 247-255.

, C. B. Mankinen, And M. H. Elliott. 1974. Genetics of Lupinus VII. Outcrossing, autofertility and variability in natural populations of the nanus group. Taxon 23: 729-738.

HARrison, S., AND R. KARBAN. 1986. Effects of an early-season folivorous moth on the success of a later-season species, mediated by a change in the quality of the shared host, Lupinus arboreus Sims. Oecologia 69: 354-359.

—, AND J. L. MARON. 1995. Impacts of defoliation by tussock moths (Orgyia vetusta) on the growth and reproduction of bush lupine (Lupinus arboreus). Ecological Entomology 20: 223-229.

Hartl, D. L. 1988. A primer of population genetics. Sinauer, Sunderland, Massachusetts, USA.

Hessing, M. B. 1988. Geitonogamous pollination and its consequences in Geranium caespitosum. American Journal of Botany 75: 13241333.

Holsinger, K. E. 1986. Dispersal and plant mating systems: the evolution of self-fertilization in subdivided populations. Evolution 40: 405-413.

-1 1991. Inbreeding depression and the evolution of plant mating systems. Trends in Ecology and Evolution 6: 307-308.

Horovitz, A., And J. Harding. 1983. Genetics of Lupinus. XII. The mating system of Lupinus pilosus. Botanical Gazette 144: 276-279.

Husband, B. C., And D. W. Schemske. 1995. Magnitude and timing of inbreeding depression in a diploid population of Epilobium angustifolium (Onograceae). Heredity 75: 206-215.

, AND —. 1996. Evolution of the magnitude and timing of inbreeding depression in plants. Evolution 50: 54-70.

Johnston, M. O. 1992. Effects of cross and self-fertilization on progeny fitness in Lobelia cardinalis and L. siphilitica. Evolution 46: 688-702.

JuncosA, A. D., AND B. D. Webster. 1989. Pollination in Lupinus nanus subsp. latifolius (Leguminosae). American Journal of Botany 76: $59-66$.

KALISZ, S. 1989. Fitness consequences of mating system, seed weight and emergence date in a winter annual, Collinsia verna. Evolution 43: $1263-1272$.

KAROLY, K. 1992. Pollinator limitation in the facultatively autogamous annual, Lupinus nanus (Leguminosae). American Journal of Botany 79: $49-56$.

1994. Inbreeding effects on mating system traits for two species of Lupinus (Leguminosae). American Journal of Botany 81: $1538-1544$.

KitTElson, P. M. 1998. Genetic structure in a population of bush lupine (Lupinus arboreus): influence of mating system, gene flow and selection. Ph.D. dissertation, University of California, Davis, California, USA.

LANDE, R., AND D. W. SCHEMSKE. 1985. The evolution of self-fertilization and inbreeding depression in plants. I. Genetic models. Evolution 39: 24-40.

,-- , AND S. J. Schultz. 1994. High inbreeding depression, selective interference among loci and the threshold selfing rate for purging recessive lethal mutations. Evolution 48: 965-978.

Levin, D. A., And H. W. Kerster. 1974. Gene flow in seed plants. Evolutionary Biology 7: 139-220.

LloYD, D. G. 1992. Self- and cross-fertilization in plants. II. The selection of self-fertilization. International Journal of Plant Sciences 153: 370-380.

- AND D. J. Schoen. 1992. Self- and cross-fertilization in plants. I. Functional dimensions. International Journal of Plant Sciences 153: 358-369.

LORD, E. M., AND Y. Heslop-Harrison. 1984. Pollen-stigma interaction in the Leguminosae: stigma organization and the breeding system in Vicia faba L. Annals of Botany 54: 827-836.

Loveless, M. D., AND J. L. HAMriCK. 1984. Ecological determinants of genetic structure in plant populations. Annual Review of Ecology and Systematics 15:65-95.

MAKI, M. 1993. Outcrossing and fecundity advantage of females in gynodioecious hionographis japonica var. kurohimensis (Liliaceae). American Journal of Botany 80: 629-634.

MARON, J. L. 1997. Interspecific competition and insect herbivory re- 
duce bush lupine (Lupinus arboreus) seedling survival. Oecologia 110: $284-290$

. 1998. Insect herbivory above- and below-ground: Individual and joint effects on plant fitness. Ecology 79: 1281-1293.

, AND P. G. ConNors. 1996. A native nitrogen-fixing shrub facilitates weed invasion. Oecologia 105: 302-312.

, AND E. L. Simms. 1997. Effect of seed predation on seed bank size and seedling recruitment of bush lupine (Lupinus arboreus). Oecologia 111: 76-84.

Mitchell-Olds, T., AND D. M. WALleR. 1985. Relative performance of selfed and outcrossed progeny in Impatiens capensis. Evolution 39: 533-544.

MurawsKi, D. A., AND K. S. BAWA. 1994. Genetic structure and mating system of Stemonoporus oblongifolius (Dipterocarpaceae) in Sri Lanka. American Journal of Botany 81: 155-160.

PAZY, B. 1984. Insect induced self-pollination. Plant Systematics and Evolution 144: 315-320.

RichARDS, A. J. 1986. Plant breeding systems. George Allen \& Unwin, London, UK.

RITLAND, K. 1990. A series of FORTRAN computer programs for estimating plant mating systems. Journal of Heredity 81:235-237.

SchaAl, B. A. 1980. Measurement of gene flow in Lupinus texensis. Nature 284: 450-451.

- AND W. J. LEVERICH. 1980. Pollination and banner markings in Lupinus texensis (Leguminosae). Southwestern Naturalist 25: 280-282.

Schemske, D. W. 1983. Breeding system and habitat effects on fitness components in three neotropical Costus (Zingiberaceae). Evolution 37: 523-539.

, AND R. LANDE. 1985. The evolution of self-fertilization and inbreeding depression in plants: II. Empirical observations. Evolution 39: 41-52.

Schoen, D. J., AND A. H. D. Brown. 1991. Whole- and within-flower self-pollination in Glycine argyrea and G. clandestina and the evolution of autogamy. Evolution 45: 1651-1665.

Shaw, D. V., AND R. W. Allard. 1982. Estimation of outcrossing rates in Douglas-fir using isozyme markers. Theoretical and Applied Genetics 62: 113-120.

Slatkin, M. 1985. Gene flow in natural populations. Annual Review of Ecology and Systematics 16: 393-430.

Stephenson, A. G., AND J. A. Winsor. 1986. Lotus corniculatus regulate offspring quality through selective fruit abortion. Evolution 40: 453-458.

Strong, D. R., J. L. Maron, P. G. Connors, A. V. Whipple, S. HarRISON, AND R. L. JEFFRIES. 1995. High mortality, fluctuation in numbers, and heavy subterranean insect herbivory in bush lupine, Lupinus arboreus. Oecologia 104: 85-92.

SYSTAT. 1997. SYSTAT for windows, Statistics, version 7 ed. SYSTAT, Evanston, Illinois, USA.

Thomson, J. D., AND S. C. H. BARRetT. 1981. Temporal variation in gender in Aralia hispida Vent. (Araliaceae). Evolution 35: 10941107.

Uyenoyama, M. K., And D. M. Waller. 1991. Coevolution of selffertilization and inbreeding depression. I II III. Theoretical Population Biology 40: 14-46, 47-77, 173-210.

WAINWRIGHT, C. M. 1978. The floral biology and pollination ecology of two desert lupines. Bulletin of the Torrey Botanical Club 105: $24-38$.

Wallace, A. T., W. T. Hanson, and P. DeCKer. 1954. Natural crosspollination in blue and yellow lupines. Agronomy Journal 46: 5960.

Weller, S. G., AND R. ORNDUfF. 1991. Pollen tube growth and inbreeding depression in Amsinckia grandiflora (Boraginaceae). American Journal of Botany 78: 801-804.

Wendel, J. F., AND N. F. WeEDEN. 1990. Visualization and Interpretation of Plant Isozymes. In D. E. Soltis and P. S. Soltis [eds.], Isozymes in plant biology, 5-45. Chapman and Hall, London, UK.

WeRTH, C. R. 1985. Implementing an isozyme laboratory at a field station. Virginia Journal of Science 36 (1): 53-76.

Wright, S. 1922. Coefficients of inbreeding and relationship. American Naturalist 56: 330-338.

WyatT, R. 1983. Pollinator-plant interactions and the evolution of breeding systems. In L. Real [ed.], Pollination biology, 51-95. Academic Press, Orlando, Florida, USA. 